\title{
Los escritos de Robert K. Merton en español: reseña bibliográfica
}

Esta bibliografía pretende ser exhaustiva. Sin embargo, las limitaciones de las bibliotecas y centros de documentación latinoamericanos siempre dejan la duda de haber omitido algún texto. Si así fuera, solicitamos a los lectores de la Revista Colombiana de Educación nos hagan saber las respectivas ausencias a fin de completar el registro. Como se sabe, estos inventarios son de gran utilidad tanto para los investigadores como para los profesores y estudiantes de los cursos de teoría sociológica e historia del pensamiento social.

El año que precede a cada uno de los textos, indica la primera edición en español, y el año entre corchetes alude a la publicación original en inglés. La comparación entre estas fechas sugiere al momento la contemporaneidad o retraso de la recepción de los escritos rnertonianos en lengua española. Según nuestro rastreo, una muestra significativa de los textos de Merton ha sido vertida al castellano, pero ello no debe llevar a olvidar que todavía restan por traducir tres importantes obras que sin duda contribuirían a alcanzar un mayor conocimiento de sus logros intelectuales y académicos. En primer lugar, el libro Mass Perssuation de 1946, que estudia el impacto de los medios de comunicación de masas a partir de la evaluación de un exitoso programa radial de venta de bonos de guerra. En segundo lugar, el volumen de 1977 The Sociology of Science: An Episodic Memoir, que ofrece una relación personal del nacimiento y desarrollo de la sociología de la ciencia. Y por último, la colección de ensayos de 1982 Social Reseavch and the Practicing Professions, que reúne varios trabajos sobre sociología de las profesiones y los fundamentos sociales y culturales que circundan la investigación social.

Gonzalo Cataño

\section{Libros y compilaciones}

1963 [1951] Con Patricia S. West, Marie Jahoda y S Selvin (eds.), Sociología de la vivienda (Buenos Aires: Ediciones 3). Trad. de Estela Falicov.

1964 [1949 y 1957] Teoría y estructura sociales (México: Fondo de Cultura Económica). Trad. de Florentino M. Torner. Colección de ensayos publicados originalmente entre 1936 y 1956. La misma casa editorial publicó en 1980 la edición norteamericana ampliada de 1968, considerada ahora como la definitiva. Trad. de F. M. Torner y Rufina Borques. Reimpresa en 1995.

1977 [1973] La sociología de la ciencia, compilación e introducción de Norman W. Storer (Madrid: Alianza), 2 vols. Trad. de Néstor A. Míguez. Colección de ensayos publicados originalmente entre 1938 y 1972.

1977 [1959] La sociología (Buenos Aires: Paidós). Versión castellana de los primeros tres ensayos de Sociology Today (comp. por R. K. Merton, L. Broom y L. S. Cottrell.,Jr.). Esta obra colectiva fue publicada por la Editorial Paidós en cinco pequeños volúmenes con títulos y autores distintos:
a)R. K. Merton y otros, La sociología.
b)S. M. Lipset y otros, Sociología política y de otras instituciones.
c)A. Inkeles y otros, El grupo y la persona.
d)K. Davis y otros, Demografía y estructura social.
e) Cohen y otros, La sociología aplicada. 
1980 [1976] Ambivalencia sociológica y otros ensayos (Madrid: Espaza-Calpe). Trad. de José L. López Muñoz. Colección de ensayos publicados originalmente entre 1936 y 1975.

1984 [1938 y 1970] Ciencia, tecnología y sociedad en la Inglaterra de/ siglo XVII (Madrid: Alianza). Trad. de Néstor Míguez.

1990 [1965 y 1985] A hombros de gigantes: posdata shandiana (Barcelona: Península). Trad. de Enrique Murillo.

\section{Ensayos}

1953 [1945J "Sociología del conocimiento", en Georges Gurvitch y R. K. Merton, Sociología del conocimiento (Buenos Aires: Editorial Deucalión), pp. 51-126. Trad. de Daniel Cruz Machado. Publicado nuevamente en Georges Gurvitch y W. E. Moore (comps.), Sociología del siglo XX(Buenos Aires: El Ateneo, 1956), vol. I, pp. 337-73. Trad. De Constantino Dimitri.

1960 [1938 y 1949] "Ritualismo", en Peter Heinz (ed.), Sociología de/ poder (Santiago de Chile: Editorial Andrés Bello), pp. 195-99. Extracto del ensayo "Estructura social y anomia". Trad. de Enrique Marshall y Ljubo Yurjevic.

1960 [1939 y 1949] "Estructura burocrática y personalidad", en Peter Heinz (ed.), Sociología de/ poder (Santiago de Chile: Editorial Andrés Bello), pp. 200-12. Trad. de Enrique Marshall y Ljubo Yurjevic.

1960 [1946] "La entrevista focalizada". Cuadernos de Sociología, Facultad de Filosofía y Letras de la Universidad de Buenos Aires, No. 21, pp. 167-86. Trad. de Cecilia Durruy.

1960 [1957]Teoría social y estructura social (Santiago de Chile: Cuadernos de FLACSO). 4 estudios.

1961 [1961] "El conflicto social en torno a los estilos de la obra sociológica". Revista de Ciencias Sociales, vol. V, No. 2, Río Piedras, junio, pp. 105-32. Trad. de José E. González.

1962 [1960] "El mosaico de las ciencias de la conducta". Revista de Ciencias Sociales, vol. VI, No. 1, Río Piedras, marzo, pp. 5-24. Trad. de José E. González. Publicado nuevamente en Bernard Berelson (ed.), El hombre: su comportamiento (México: PaxMéxico, 1968).

1964 [1937] "Sociología del conocimiento", en I. L. Horowitz (comp.), Historia y elementos de la sociología del conocimiento (Buenos Aires: Eudeba), vol. I, pp. 65-75. Trad. de Noemí Rosenblatt.

1964 [1948] "La profecía que se autorrealiza", cii Colección Derechos Humanos (Buenos Aires: Ediciones D.A.I).

1964 [1963] "La ambivalencia de los científicos". Revista de Occidente, No 10, Madrid, enero, pp. 44-70.

1967 [1964] "Anomia, anomia e interacción social: contextos de conducta desviada", en Marshal B. Clinard (comp.), Anomia y conducta desviada (Buenos Aires: Paidós), pp. 201-26. Trad. de J. J. Thomas.

1969 [1948] Con Paul F. Lazarsfeld, "Los medios de comunicación de masas, el gusto popular y la acción social organizada", en Daniel Bell et al., Industria cultural y sociedad de masas (Caracas: Monte Ávila), 251-81. Trad. de Eugenio Guasta. Traducido nuevamente en Lazarsfeld y otros, La comunicación de masas, introducción y selección de textos de Heriberto Muraro (Buenos Aires: Centro Editor de América Latina, 1978), pp. 25-47.

1970 [1949] "Estructura social y anomia", en Erich Fromm et al., La/ familia (Barcelona: Península), pp. 67-106. Trad. de Jordi Solé Tura. 
1974 [1946] "Definiciones de una situación", en R. Boudon y P. F. Lazarsfeld (comps.), Metodología de las ciencias sociales (Barcelona: Laía), vol. II, pp. 163-62. Trad. (del francés) de Josep Colomé. Extracto del libro Mass Persuasion.

1975 [1954] Con Paul F. Lazarsfeld, "La amistad corno proceso social", en F. Chazel, R. Boudon y P. F. Lazarsfeld (comps.), Metodología de las ciencias sociales (Barcelona: Laia), vol. III, pp. 321-43. Trad. (del francés) de Jaime Melendres. Extractos.

1979Jesús L. García., Merton: la estructura precaria, orden y conflicto en la sociedad moderna (México: Editorial Edicol). Las páginas 100-91 contienen traducciones de varios textos de Merton.

1992 [1937] Con Pitirim A. Sorokin, "El tiempo social: un análisis metodológico y funcional", en Ramón Ramos Torres (comp.), Tiempo y sociedad (Madrid: Siglo XXI), pp. 73-87. Trad. de R. Ramos Torres

1992 [1984] "Las duraciones esperadas socialmente: un estudio de caso sobre la formación de conceptos en sociología", en Ramón Ramos Torres (comp.), Tiempo y sociedad (Madrid: Siglo XXI), pp. 275-306. Trad. de ASEL, SA.

1996 [1994] "Una vida de aprendizaje". Revista Colombiana de Educación, No. 33, Bogotá. pp. 103-25. Trad. de Libardo González. Reproducido en Revista Paraguaya de Sociología, No. 100, sept.-dic. de 1997, pp. 7-33.

\section{Prólogos}

1963 [1950] "Introducción" a George C. Homans, El grupo humano (Buenos Aires: Eudeba), pp. 19-25. Trad. de M. Reilly de Frayard.

1963 [1953] "Prefacio" a Hans Gerth y C. Wrigth Mills, Carácter y estructura social (Buenos Aires: Paidós), pp. 11-12. Trad. de Elizabeth Gerlin y Jorge Balán.

1965 [1960] "Prólogo" a Harry M. Johnson, Sociología (Buenos Aires: Paidos), pp. 9-11. Trad. de E. Kostelboim y J. Topf.

1972 [1970] "Introducción" a Imogen Seger, El libro de la sociología moderna (Barcelona: Omega), pp. 7-IO. Trad. de Herminia Dauer.

1975 [1975] "Introducción a un libro de Marías" [La estructura social]. Revista de Occidente, No. 148, Madrid, julio, pp. 99-111. 